\title{
On the Use of Outcomes to Connect Students to an Engineering Identity, Cul- ture, and Community
}

\section{Prof. Rebecca A. Bates, Minnesota State University, Mankato}

Rebecca A. Bates received the Ph.D. degree in electrical engineering from the University of Washington in 2004. She also received the M.T.S. degree from Harvard Divinity School in 1993. She is currently a Professor in the Department of Integrated Engineering program at Minnesota State University, Mankato, home of the Iron Range and Twin Cities Engineering programs. She is also a program director at the National Science Foundation for TCUP and HBCU-UP in the Division of Human Resource Development.

\section{Dr. Cheryl Allendoerfer, University of Washington}

Dr. Allendoerfer is a Research Scientist in the College of Engineering at the University of Washington.

\section{Mr. Ronald R. Ulseth, Itasca Community College}

Ron Ulseth directs and instructs in the Iron Range Engineering program in Virginia, Minnesota and he teaches in the Itasca Community College engineering program in Grand Rapids, MN. He was instrumental in growing the Itasca program from 10 students in 1992 to 160 students in 2010. In 2009, he worked with a national development team of engineering educators to develop the 100\% PBL curriculum used in the Iron Range model. He has successfully acquired and managed over $\$ 10$ million in educational grants including as PI on 7 grants from NSF. He has been in the classroom, teaching more than 20 credits per year to engineering students for more than 25 years. His specific areas of expertise are in active learning, faculty development, and learning community development. He has been awarded the 2012 Progress Minnesota award, 2012 Labovitz Entrepreneurialism award, and 2012 Innovator of the Year award from the Rural Community College Alliance all for his work in developing the Iron Range Engineering program. His degrees are in civil engineering (B.S., University of North Dakota), and mechanical engineering (M.S., University of Central Florida). He is licensed as a professional engineer in the state of Minnesota.

\section{Bart M. Johnson, Itasca Community College}

Bart Johnson is the Provost of Itasca Community College. Prior to this position, he was the Dean of Academic Affairs and an engineering instructor and program coordinator at Itasca. His areas of engineering education research focus are project-based learning, learning communities, professional identity development, and professional competencies. Prior to Itasca, he was an engineer in John Deere's Construction and Forestry Division and a research fellow for Whirlpool Corporation. 


\section{On the Use of Outcomes to Connect Students to an Engineering Culture, Identity, and Community}

Change is hard, a truism that can be highlighted in engineering education in many ways. The momentum of engineering education in traditional forms, and even the experiences of people in professional careers, is hard to shift, but many have tried. ${ }^{1}$ One can argue that the shift to ABET's EC2000 outcomes-based assessment was meant to serve as a change agent, but after a decade of implementation, engineering education looked pretty much the same. Small changes in programs sometimes stuck, and sometimes programs faded back to the way they were before any interventions were attempted. With the idea that maybe things could be different, that maybe change could last, a group of engineering educators got together to imagine what an engineering program could look like if the traditional constraints did not matter, only the outcomes.

The product of this creative work is Iron Range Engineering, a program designed to develop students who meet all of the outcomes defined in Criterion $3,{ }^{2}$ but have a different learning experience. Iron Range Engineering (IRE) is a project-based learning program that uses the outcomes to help students know when they are being engineers. This paper will tell the story of how the ABET outcomes have been and are used to drive innovative change in engineering education. It will tell the story of how they affect our students and our graduates, supporting and reinforcing their sense of identity as engineers, creating a culture that encourages the ongoing development of engineers and connecting them to a local, national, and international community where they can persist in engineering careers.

The paper is organized around motivating concepts, supported by Schein's model of organizational culture, where artifacts that represent actions are the visible level, the next is espoused values, and the third level is assumed values or basic underlying assumptions, and can be represented by beliefs and identity. ${ }^{3}$ Ultimately, the outcomes we aim to meet, shown through artifacts, represent the values we hold as a community. Creating a culture that represents these values and supports meeting outcomes can best be done intentionally, and is monitored through a continuous improvement process. These support the development of an engineering identity and the process of students growing and developing into members of the community, whether defined as the academic or professional community.

The context of this paper and its reflection on the use of outcomes to design and operate an engineering program is the proposal for significant changes in the ABET criteria. Discussions amongst the ASEE community have included webinars, a virtual conference, and a town hall meeting at the 2016 ASEE conference. ${ }^{4}$ The goal of this paper is to provide an example of how outcomes have been used as a driver and motivator for innovative change in engineering education.

\section{Values}

The outcomes currently defined in Criterion 3 are a clear statement of the values the broad engineering community holds, such as use of foundational information to solve problems, lifelong learning, communication, and ethical behavior. At IRE, and its sister program Twin Cities 
Engineering (TCE), incoming students are presented with the outcomes during orientation. As new, innovative programs recruiting students before being accredited, discussion of the outcomes and aligning program activities with the outcomes provided external credibility. This supported change and student buy-in to program activities that were designed to move them towards better meeting the outcomes, but that would not be familiar to students in traditional programs, such as a professional development plan or metacognitive reflection activities.

The IRE and TCE programs were developed as outcomes-based programs. Beginning with the ABET Criterion 3 a-k outcomes, engineering faculty from around the United States who were well versed in education research imagined the best way to get to those outcomes if they could start from the ground up..$^{5}$ Given that the outcomes are used to establish values, pedagogical approaches that support learning all outcomes in an integrated fashion make sense. In a context of solving ill-structured, open-ended problems to complete a project, defining technical content at a curricular level makes less sense. The implementation of that vision uses project-based learning to teach engineering design, professional skills and technical competencies to upperdivision students. Reflecting values also held by the greater community, the programs also include outcomes in leadership, entrepreneurship and inclusivity.

Leadership and entrepreneurship outcomes were added early in the development of IRE. As part of our continuous improvement process, external feedback from invited evaluators showed that there were issues with gender roles assumed in projects. Women were more likely to take on roles related to communication; men were more likely to go to the shop and build prototypes. In the spring of 2014, Rose Marra and Barbara Bogue did an initial diversity study and one of their findings was that it was not just an issue of taking on roles, but an issue of inclusivity. Examples of issues were that women students felt that their voices were not being heard in project discussions and that they were being talked over. A set of recommendations included having inclusivity as a front-burner topic in seminars and faculty meetings, the addition of a program outcome, and the culture-building concept of "Agents of Change," recognition of those who understand unconscious bias and have the courage to step forward and seek positive, pro-active change, whether in a project group, a class, an internship, or in their careers after graduation.

Both IRE and TCE have sets of core values that are part of the programmatic context (shown in Table 1). While these are social constructs, they align closely with the ABET outcomes, with the key addition of our inclusivity outcome. Posters of these values hang on the walls at both programs and are discussed with students. The connection between how things are done and what is done are made to both values and program outcomes.

Table 1: IRE \& TCE Core Values

\begin{tabular}{|c|c|}
\hline Twin Cities Engineering & Iron Range Engineering \\
\hline - Self-motivated \& self-directed learning & - Service to others \\
- Student ownership & - Self-directed learning \\
- Community & - Embracing and fostering an individual's unique \\
- Continuous Improvement & $\begin{array}{c}\text { learning goals and trajectory to their profession } \\
\text { - Reflection }\end{array}$ \\
- Communication & - Reflectiveness as an essential part of learning \\
$\bullet$ Deadlines & Becoming agents of change with the courage to act \\
\hline
\end{tabular}




\section{Culture}

Creating a culture that reflects these values includes structuring the use of outcomes so that they are meaningful to both students and faculty. Rather than use a-k, or a-n in our case, as descriptors, the outcomes are divided into technical, design, and professional outcomes (see Table 2). While some could arguably be in other categories, these designators create a shorthand for discussing student growth in key areas and for structuring portfolio evidence for outcomes.

Adding a new outcome required a culture change at IRE. This addition was facilitated with workshops for both faculty and students on unconscious bias and other topics, open conversation about issues related to inclusivity, individual behavior and the impact on teams, and the Agents of Change award that recognizes people who work to modify the culture, even when there is the potential for personal risk.

Additional work has been done at Iron Range Engineering with both students and faculty participating to rephrase outcomes to have more personal meaning. Along with the descriptions of the outcomes, the processing work to consider them - to connect to them personally, and to clearly define them so that they can be easily internalized - contributes to a culture that reinforces the community values associated with being an engineer. The rephrased outcomes are shown in Figure 1, which is a poster hung in the large seminar room at IRE.

Table 2: IRE \& TCE Program Outcomes

\begin{tabular}{|l|l|l|}
\hline \multicolumn{1}{|c|}{ Technical } & \multicolumn{1}{|c|}{ Design } & \multicolumn{1}{c|}{ Professional } \\
\hline $\begin{array}{l}\text { An ability to apply } \\
\text { knowledge of mathematics, } \\
\text { science, and engineering } \\
\text { (ABET A) }\end{array}$ & $\begin{array}{l}\text { An ability to design a system, } \\
\text { component, or process to meet } \\
\text { desired needs within realistic } \\
\text { constraints such as economic, } \\
\text { environmental, social, political, } \\
\text { ethical, health and safety, } \\
\text { manufacturability, and } \\
\text { sustainability (ABET C) }\end{array}$ & $\begin{array}{l}\text { An understanding of } \\
\text { professional and ethical } \\
\text { responsibility (ABET F) }\end{array}$ \\
\hline $\begin{array}{l}\text { An ability to design and } \\
\text { conduct experiments, as well } \\
\text { as to analyze and interpret } \\
\text { data (ABET B) }\end{array}$ & $\begin{array}{l}\text { An ability to function on } \\
\text { multidisciplinary teams (ABET D) }\end{array}$ & $\begin{array}{l}\text { An ability to communicate } \\
\text { effectively (ABET G) }\end{array}$ \\
\hline $\begin{array}{l}\text { An ability to identify, } \\
\text { formulate, and solve } \\
\text { engineering problems } \\
\text { (ABET E) }\end{array}$ & $\begin{array}{l}\text { An ability to lead, manage people } \\
\text { and projects (ABET L) }\end{array}$ & $\begin{array}{l}\text { A knowledge of } \\
\text { contemporary issues } \\
\text { (ABET J) }\end{array}$ \\
\hline $\begin{array}{l}\text { A recognition of the need for, } \\
\text { and an ability to engage in } \\
\text { life-long learning (ABET I) }\end{array}$ & $\begin{array}{l}\text { An ability to use the techniques, } \\
\text { skills, and modern engineering } \\
\text { tools necessary for engineering } \\
\text { practice (ABET K) }\end{array}$ & $\begin{array}{l}\text { An ability to work } \\
\text { successfully in a diverse } \\
\text { environment (ABET N) }\end{array}$ \\
\hline $\begin{array}{l}\text { An ability to engage in } \\
\text { entrepreneurial activities } \\
\text { (ABET M) }\end{array}$ & $\begin{array}{l}\text { The broad education necessary to } \\
\text { engineering solutions in a global, } \\
\text { economic, environmental, and } \\
\text { societal context (ABET H) }\end{array}$ & \\
\hline
\end{tabular}




\section{Iron Range Engineering}

\section{Being an Engineer}

- Perform on teams

- Write technical documents

- Give presentations

- Be a self-directed learner

- Conduct experiments [design, conduct, analyze]

- Know and use fundamental principles

- Be reflective

- Solve open-ended problems

- Design systems and components to constraints and contexts

- Act ethically

- Be professionally responsible

- Know contemporary issues

- Lead people

- Manage projects

- Act entrepreneurially

- Be inclusive

- Use modern tools

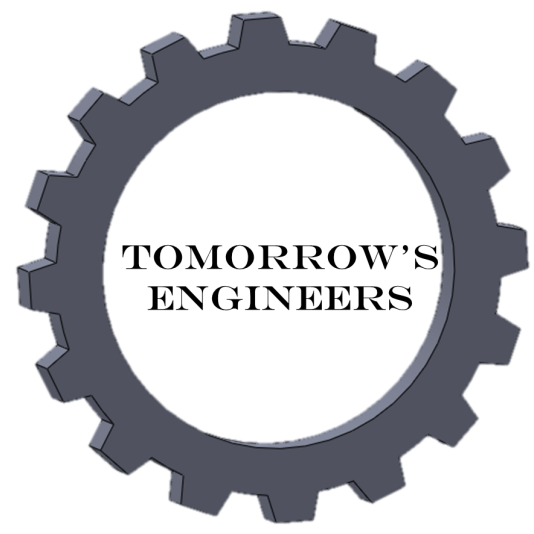

- Embrace continuous improvement

Figure 1: Being an Engineer 
Moving beyond what the outcomes are, there is the issue of how the outcomes are met. Performance indicators that match the work of our programs and allow students to show they understand were first developed by National Academic Advisory Board member Denny Davis and then revised with feedback from other board members, faculty, the TCE Industry Advisory Board and students. Figure 2 is the poster shown on Twin Cities Engineering walls and presented to all students during incoming student orientation. It is also used as the cover page for student portfolios, so is revisited through each of their four semesters as they gather portfolio evidence for each outcome.

In gathering portfolio evidence, students go beyond the straightforward administrative task of gathering copies of work they have done and write a brief statement that reinforces their learning. The statement should assert in what way this particular evidence demonstrates the meeting of the outcome. It could be as simple as stating that external evaluation of the work shows the work is above expectations, or that the trajectory of evidence across four semesters shows clear improvement.

The examples provided here show how outcomes function as core values in two engineering programs. When these outcomes are addressed and available in shared spaces, they help create a culture in which these outcomes and values are shared and reinforced.

\section{Continuous Improvement}

An overarching value of continuous improvement, which is held and practiced by faculty programmatically and individually, reinforces the idea of life-long learning. Our practices of pre- and post-semester reflection, including solicitation of feedback from multiple stakeholders including students, demonstrates this value to students. A key example of this process is the addition of our inclusivity outcome, which was the result of external feedback, faculty and student reflection, and willingness to immediately introduce a change that could positively affect student experiences and learning.

Another example of continuous improvement is feedback from industry advisory board members at Twin Cities Engineering that significantly modified the performance indicators for the entrepreneurship outcome. The addition of the indicator "Ability to learn through failure" that supports the outcome of an "Ability to engage in entrepreneurial activities" has led to significant work highlighting failure as an opportunity to learn and to prompt open discussion about experiences that are often hidden (occasionally with difficult consequences, e.g., the Volkswagen turbo diesel scandal). ${ }^{6}$

This value of continuous improvement is also shown in program activities through assignments that address student development. Students create a professional development plan each semester addressing the areas shown in Table 3. As they move through the program, students reflect on their performance, evaluate their development and construct a plan for the following semester. Graduating seniors develop plans that they can take into their first job, or into graduate school. In programmatic improvement, we have moved from written documents that reflect the ideals of academic writing to documents that mirror similar professional development plans for practicing engineers. Feedback on these plans as well as meetings with project facilitators and 


\section{$\stackrel{2}{2}$ Twin Cilies Engineering}

\section{Technical Outcomes}

Tech 1 . An ability to apply knowledge of mathematics, science, and engineering

- Describe concepts in an oral exam.

- Solve closed-ended problems.

- Use knowledge in a deep learning activity.

Tech 2. An ability to design and conduct experiments, as well as to analyze and interpret data

- Design an experiment to answer a question related to technical work.

- Acquire experimental data and compare results to appropriate variables.

- Explain observed differences between model and experiment and offer explanations.

Tech 3. An ability to identify, formulate, and solve engineering problems

- Choose and apply appropriate engineering principles needed to solve an open-ended problem.

- Determine the reasonableness of a solution to an open-ended problem

- Evaluate the completed solution process to determine effectiveness.

Tech 4. A recognition of the need for, and an ability to engage in life-long learning

- Describe principles of effective learning.

- Develop and communicate personal learning model.

- Apply Metacognition techniques to improve individual learning.

Tech 5. An ability to engage in entrepreneurial activities

- Recognizes the financial impacts of the proposed design

- Choose and apply business concepts to products and processes.

- Aware of the value of innovation and the impact of risk on engineering decision making.

- Able to learn through failure.

- Able to use resources wisely \& creatively.

- Able to address engineering, business or societal problems creatively.

\section{Design Outcomes}

Design 1. An ability to design a system, component, or process to meet desired needs within realistic constraints

- Accurately report a scoping process for a project in writing and verbally.

- Conduct the design process iteratively to develop a solution meeting the requirement.

- Critically judge design solution effectiveness based on project requirements.

Design 2. An ability to function on

multidisciplinary teams

- Establish a team contract setting team expectations and assign appropriate roles.

- Analyze effectiveness of the group during the project.

- Evaluate quality of teamwork achieved and its impact upon satisfying project requirements.

- Individually contribute appropriately to completion of team project.

Design 3. An ability to lead, manage people and projects

- Create a team time budget based on a list of tasks within a project.

- Implement a team course of action to finish all required tasks by a deadline.

- Evaluate effectiveness of one's ability to lead, manage people, and manage projects; develop a plan for future improvement

Design 4. An ability to use the techniques, skills, and modern engineering tools necessary for engineering practice

- Document a wide range of acquired technical skills and techniques through the development of a "best works" portfolio of their engineering practice.

- Document acquisition of and growth in professional skills and techniques through periodic personal performance evaluations.

- Solve advanced engineering calculations and perform design analysis using modern tools.

- Document design work and activities using a legally valid technical notebook.

Design 5. The broad education necessary to understand the impact of engineering solutions in a global, economic, environmental, and societal context

- Identify and apply contextual knowledge that influences design solutions. Examples include, but are not limited to: health, safety, environment, global, societal, ethical, moral, legal, financial, human, and lifecycle.

\section{Professional Outcomes}

Prof 1. An understanding of professional and ethical responsibility

- Write professional development improvement plans, semester by semester.

- Actively participate in multiple outreach activities per semester.

- Take part in and document regular design project ethical implication conversations.

- Meet the Professional Expectations of a TCE student.

- Aware of nondisclosure agreements.

Prof 2. An ability to communicate effectively

- Communicates project details verbally to various audiences.

- Communicate technical information to student peers

- Analyze individual communication effectiveness and develop an improvement plan.

- Evaluate others' writing and presentations and provide feedback.

- Complete "Jobs Package".

- Communicate with project clients or outreach coordinators in a professional manner.

Prof 3. A knowledge of contemporary issues

- Demonstrate awareness of contemporary issues.

Prof 4*. An ability to work successfully in a diverse environment

- Write PDP goals that show that interacting with others in a professional and respectful manner in all situations is a critical tool for success.

- Maintain a daily work environment free from behaviors and speech that cannot be tolerated in an engineering environment.

- Demonstrate an understanding of unconscious bias and its implications.

- Demonstrate respect for and awareness of inclusive decision processes.

The goal of Twin Cities Engineering is to graduate engineers ready to meet the demands of engineering practice. It is our belief that students who can meet the above outcomes at an acceptable level are ready to meet these demands and become engineering professionals.

\section{Figure 2: Outcomes \& Performance Indicators}


Table 3: Professional Development Plan Topics

\begin{tabular}{|cc|}
\hline Ability to function on a team & Meeting professional expectations \\
Acting ethically & Technical writing effectiveness \\
Presentation effectiveness & Metacognitive effectiveness \\
Respecting diversity/inclusivity & Contemporary issues \\
Ability to lead and manage people
\end{tabular}

advising faculty to discuss performance are used by students to normalize self-assessment of their professional development.

One example of programmatic improvement based on observations from our National Academic Advisory Board is that students can articulate their professional development, particularly related to professional outcomes, but sometimes struggle to discuss their own technical growth, or to think of themselves as strongly technical engineers. By expanding our focus to embrace design and professional outcomes, some students may feel that they are not as technical as graduates of traditional programs that may emphasize technical learning. The result is an additional document assigned to map out technical learning plans each semester, including reflections on technical growth. Design development reflection is done in the context of team project work and has been embedded in final design presentations.

\section{Identity}

Being an engineering student is not always easy. Other work has shown the relationship between identity and retention. ${ }^{7}$ Creating a culture that supports the development of engineering identity can take advantage of program outcomes to reinforce this idea. At IRE and TCE, the program outcomes are used to answer the question of "Why am I doing this?" Because this work is how you are an engineer. This is what the local and broader communities say is required of an engineer. Even when the work is difficult, or does not play to personal strengths, the breadth of these outcomes is important to being a complete engineer.

While the outcomes have driven faculty planning, they were not always used explicitly in the program. Although outcomes and performance indicators are part of regular discussion and development, originally, they were only explicit to students in the program through portfolio creation. The outcomes have always guided the program activities and have been used to justify activities, whether made explicit or not. As noted earlier, explicitly working with outcomes is currently part of the community practice at both IRE and TCE. This work of explicitly talking about what it means to be an engineer can be seen as reinforcement and development of engineering identities. Initially, portfolio work focused on accreditation needs and external evaluation. Currently, portfolio creation is presented as supporting the student in showing how they are engineers. Even in initial orientation, where students have completed lower-division math, science and engineering requirements, conversations happen about how students are already meeting the outcomes, which outcomes do they need further development in, and how might they use their four semesters of project experiences to grow in all areas.

Studies looking at the professional and technical development of our graduates have been done with interesting findings related to the outcomes. In one study, students self-reported assessment 
of their performance in actions related to professional outcomes as well as their understanding of the importance of these outcomes to their personal and project success. Results taken from the dissertation work of Bart Johnson show two key findings. ${ }^{8}$ In a longitudinal study of students in both project-based learning (PBL) and non-PBL programs, results showed that performance in professional outcomes, in both individual and team contexts, had a significant positive difference for PBL students and no significant change for non-PBL students. While these results supports the pedagogical approach, the result related to importance of these professional outcomes showed a significant negative difference for non-PBL students for the individual context. While the personal valuing of professional outcomes is a result of a lifetime of experiences and influences, the culture of valuing these outcomes reinforces the importance for PBL students. The meshing of personal and professionally-sanctioned values has implications for long-term persistence in the engineering field. ${ }^{9}$

In associated qualitative interviews with PBL graduates, they were able to restate professional competencies at a very high level and how they apply to them and their careers. Graduates attributed their performance improvement to the explicit professional development activities in the program, and based their assessments primarily on external feedback from project facilitators and industry liaisons. They also talked about how program activities reaffirmed the importance of the outcomes.

75 students have graduated from Iron Range Engineering and are in engineering practice. Ulseth and Johnson ${ }^{10}$ surveyed the graduates and their supervisors regarding performance in all 14 outcomes. In each case, the survey participants were asked to rate the IRE graduate in performance on the outcome on a scale from 1 to 7 and then were asked to rate the graduates peers from traditional engineering programs. In all 14 outcomes, the graduates rated themselves higher than their peers. In 13 out of the 14 outcomes, the supervisors rated the IRE graduates higher than their peers (tied on $14^{\text {th }}$ ). Many trends were identified and reported. In general, the IRE graduates substantially outperformed their peers in the professional outcomes related to teamwork, leadership, and project management as well as in self-directed learning abilities. In the technical outcomes the IRE graduates tended to perform more equal to their peers from traditional programs. Ulseth and Johnson ${ }^{10}$ concluded that there were high levels of satisfaction from the graduates on their preparation for engineering practice and from engineering supervisors on the performance of the graduates. The structure of these PBL programs, where students are treated like working engineers, contributes to abilities and affirmation of personal values, reinforcing engineering identity development.

\section{Community}

Many have argued that a sense of community and belonging is important for student engagement and persistence. ${ }^{11-15}$ A long-term project examining community and belonging at five institutions included the IRE program, where striking differences were seen in the experience of being in this community, to the extent that data could not be included with non-PBL results. ${ }^{16,17}$ In qualitative interviews, students repeatedly reported experiences of being in this together, getting through it together, and having each other's backs. The level of reported experiences and connections to community are very different from traditional programs, where students may prefer to work alone and are influenced by a more individually competitive environment. Given the values of 
community, inclusivity, and a collegial culture, as well as the outcome of being able to work on interdisciplinary teams and the breadth of the current ABET outcomes, the use of these values and outcomes to drive the team-based projects used at IRE and TCE as well as the extracurricular and co-curricular activities, creates a culture that is different from traditional programs. These communities reinforce the importance of engineering values by starting from the formal accreditation outcomes.

\section{Concluding Remarks}

As a project-based program, the weight of the external value of the outcomes is significant. Students will actively participate in the breadth of the project work, in the depth of writing and communicating, and in the connection to broader contexts, when they are assured that this is what is expected by employers and future colleagues. Faculty, evaluators, and researchers have observed that students internalize the outcomes and construct their learning and work to show how they meet these outcomes. The implication of the studies presented here, when combined with other studies looking at persistence in engineering careers, is that reinforcement of values related to the breadth of engineering activity helps develop engineering identity and can contribute to a connection between personal and professional values, leading to long-term persistence and satisfaction with career choice.

\section{Acknowledgements}

The authors thank the members of the National Academic Advisory Board, the TCE Industry Advisory Board, and the faculty and students of both IRE and TCE for their contributions to the development and ongoing improvements of both programs. Some results were supported by the NSF. [Names and grant numbers to be added in final document.]

\section{References}

1. Sheppard, S.D., Macatangay, K., Colby, A., Sullivan, W.M. (2008). Educating Engineers: Designing for the Future of the Field. San Francisco: Jossey-Bass.

2. ABET Accreditation Commission. (2016). Criteria for Accrediting Engineering Programs, 2016-2017. http://www.abet.org/accreditation/accreditation-criteria/criteria-for-accrediting-engineering-programs-20162017/ Accessed January 31, 2016.

3. Schein, E. (1992). Organizational Culture and Leadership. John Wiley \& Sons.

4. ASEE Interdivisional Town Hall Meetings Virtual Conference. March 6-8, 2016 https://aseetownhall.wordpress.com/virtual-conference/ Accessed March 18, 2016.

5. Marra, R.M., Palmer, B., Ulseth, R., Johnson, B. (2011). The Iron Range Engineering PBL curriculum: How students adapt to and function within PBL. In $3^{\text {rd }}$ International Research Symposium on PBL 2011, Coventry University, England.

6. Sleezer, R., Swanson, J., Bates, R. (2016). Using Failure to Teach Design. Submitted to Proceedings of the ASEE Annual Conference \& Exposition, New Orleans, LA, June 2016.

7. Tonso, K. (2014) Engineering Identity. In Cambridge Handbook of Engineering Education Research. A. Johri \& B.M. Olds, eds. Cambridge University Press.

8. Johnson, B. (2016). Study of Professional Competency Development in a Project Based Learning (PBL) Curriculum (Unpublished doctoral thesis). University of Aalborg, Aalborg, Denmark.

9. Wasilewski, C.H. (2015).Men and Women in Engineering: Professional Identity and Factors Influencing Workforce Retention. Industrial-Organizational Psychology Dissertations. Paper 2. Available at http://digitalcommons.spu.edu/iop_etd/2/ accessed January 31, 2016. 
10. Ulseth, R., \& Johnson, B. (2015). Iron Range Engineering PBL experience. In Proceedings of the Seventh International Symposium on Project Approaches in Engineering Education (paee'2015), Integrated in the International Joint Conference on the Learner in Engineering Education (ijclee'2015) Event.

11. Baumeister, R. F., \& Leary, M. R. (1995). The need to belong: Desire for interpersonal attachments as a fundamental human motivation. Psychological Bulletin 117(3), 497-529.

12. Pascarella, E. T., \& Terenzini, P. T. (2005). How college affects students: A third decade of research. San Francisco, CA: Jossey-Bass.

13. Hausmann, L. R. M., Schofield, J. W., \& Woods, R. L. (2007). Sense of belonging as a predictor of intentions to persist among African American and White first-year college students. Research in Higher Education, 48(7), 803-839.

14. Wilson, D., Bell, P., Jones, D., Spring, D., \& Hansen, L. (2010). Cross sectional study of belonging in engineering education. International Journal of Engineering Education, 26(3), 1-12.

15. Ohland, M. W., Sheppard, S. D., Lichtenstein, G., Eris, O., Chachra, D., \& Layton, R. A. (2008). Persistence, engagement and migration in engineering programs. Journal of Engineering Education, 97(3), $259-278$.

16. Floyd-Smith, T., Wilson, D., Campbell, R., Veilleux, N., Bates, R., Plett, M., Scott, E., \& Peter, D. (2010). A multi-institutional study of connection, community, and engagement in STEM education: Conceptual model development. In Proceedings of the ASEE (American Society for Engineering Education) Conference, Arlington, VA, June 2010.

17. Allendoerfer, C., Wilson, D., Bates, R., Crawford, J., Jones, D., Floyd-Smith, T., Plett, M., Scott, E., \& Veilleux, N. (2012). Strategic pathways for success: The influence of outside community on academic engagement. Journal of Engineering Education, 101(3), 512-538. 